\title{
The dose-volume interaction in adult supratentorial low-grade glioma: higher radiation dose is beneficial among patients with partial resection
}

\author{
C. Leighton $\cdot$ B. Fisher $\cdot$ D. Macdonald $\cdot$ L. Stitt $\cdot$ \\ G. Bauman · J. Cairncross
}

Published online: 10 July 2007

(C) Springer Science+Business Media B.V. 2007

Erratum to: J Neurooncol (2007) 82:165-170

DOI 10.1007/s11060-006-9141-1

The original version of this article unfortunately contained a mistake. The sequence of the author names was incorrect.

The correct sequence is

C. Leighton, B. Fisher, D. Macdonald, L. Stitt, G. Bauman, J. Cairncross

The online version of the original article can be found under doi: 10.1007/s11060-006-9141-1.

C. Leighton · B. Fisher $(\bowtie) \cdot$ G. Bauman

Division of Radiation Oncology, London Regional Cancer

Centre Program, London Health Sciences Hospital, London,

Ontario, Canada

e-mail: barb.fisher@1rcc.on.ca

D. Macdonald

Department of Medical Oncology, London Regional Cancer

Program and Department of Neurooncology, University

of Western Ontario, London, Ontario, Canada

L. Stitt

Department of Epidemiology and Biostatistics, University

of Western Ontario and Clinical Research Unit, London

Regional Cancer Program, London Health Sciences Hospital,

London, Ontario, Canada

J. Cairncross

Tom Baker Cancer Centre, Calgary, Alberta, Canada 